Original

\title{
Effects of demineralized bone matrix and a 'Ricinus communis' polymer on bone regeneration: a histological study in rabbit calvaria
}

\author{
José R. Laureano Filho'), Emanuel S. S. Andrade ${ }^{2)}$, José R. Albergaria-Barbosa ${ }^{3)}$, \\ Igor B. Camargo ${ }^{1)}$ and Robson R. Garcia ${ }^{4)}$ \\ ${ }^{1)}$ Oral and Maxillofacial Surgery, University of Pernambuco (UPE), Recife, Brazil \\ ${ }^{2)}$ Oral Pathology, University of Pernambuco (UPE), Recife, Brazil \\ ${ }^{3)}$ Oral and Maxillofacial Surgery, University of Campinas (Unicamp), Piracicaba, Brazil \\ ${ }^{4)}$ Oral and Maxillofacial Surgery, School of Dentistry of Paulista University (UNIP), Goiânia, Brazil
}

(Received 1 December 2008 and accepted 10 June 2009)

\begin{abstract}
The aim of the present study was to histologically analyze the effects of bovine and human demineralized bone matrix and a Ricinus communis polymer on the bone regeneration process. Two surgical bone defects were created in rabbit calvaria, one on the right and the other on the left side of the parietal suture. Eighteen rabbits were divided into three groups. In Group I, the experimental defect was treated with bovine demineralized bone matrix, Group II with human demineralized bone matrix, and in Group III, the experimental cavity was treated with polyurethane resin derived from Ricinus communis oil. The control defects were filled with the animals' own blood. The animals were sacrificed after 7 and 15 weeks. Histological analysis revealed that in all groups (control and experimental), bone regeneration increased with time. The least time required for bone regeneration was noted in the control group, with a substantial decrease in the thickness of the defect. All materials proved to be biologically compatible, but polyurethane resorbed more slowly and demonstrated considerably better results than the demineralized bone matrices. ( $\mathrm{J}$ Oral Sci 51, 451-456, 2009)
\end{abstract}

Correspondence to Dr. Jose Rodrigues Laureano Filho, Av. Visconde de Jequitinhonha, 1144/906, Boa Viagem - Recife PE, CEP 51020-030, Brazil

Tel: $+55-8197350028$

Fax: $+55-8121234855$ or $+55-8134611569$

E-mail: laureano@pq.cnpq.br
Keywords: demineralized bone matrix; bone regeneration; osteoconduction: Ricinus communis polymer.

\section{Introduction}

Bone augmentation procedures in oral and craniomaxillofacial surgery before implant insertion are most frequently carried out with autografts, allografts or composite material (1-6). However, the search for new materials for bone reconstruction in the craniomaxillofacial region is ongoing as the autogenous, allogenic, and alloplastic materials currently used have certain drawbacks.

In spite of the fact that autogenous bone continues to be the "gold standard" for bone grafting applications, the location of the harvesting site and donor site morbidity must also be considered when using autologous grafts because only a limited amount of intraoral bone is available for harvesting and grafting $(7,8)$.

Alloplastic materials also have drawbacks, particularly in a vascularly compromised environment. Tissueengineering procedures for bone augmentation of the maxilla have been the subject of recent research in an attempt to overcome the disadvantages of conventional grafts, as there is minimal or no donor site morbidity. Ideally, these procedures should be performed in outpatient settings under local anesthesia, using exclusively autologous material with bone-forming capacity. The greatest difficulty of this technique is that engineering procedures using 
living tissues in vivo require new concepts in cell culture technology. In the field of tissue engineering of bone materials, naturally derived and synthetic polymers, composites, ceramics, and bone morphogenic protein, as well as cellular systems, are being studied $(9,10)$.

Although these sources are more convenient, the predictability of healing and long-term capabilities for remodeling are questionable because normal lamellar bone is not the same as autogenous bone $(4,11,12)$. However, when allogenic, xenogenic, and alloplastic materials are used, their success and predictability can be increased with the addition of autogenous bone to create a composite graft $(4,8,12-14)$.

Although autogenous bone is the best material for use in grafts, many substitutes for bone tissue have been proposed to avoid morbidity of donor sites and increased duration of surgery. Attempts have been made to create and extract from nature, materials that promote and increase bone healing and new bone formation and that are biocompatible and osteogenic, thereby stimulating osteoinduction and osteoconduction (15).

Some polyurethane polymers have emerged as materials for biologic implants because of their mechanical properties, chemical stability, and biocompatible nature. A natural polyurethane resin made of fatty acids extracted from Ricinus communis (tropical castor bean) has recently been tested as a matrix for bone and joint replacement. Further applications of this resin in orthopedics, plastic surgery, urology, and periodontics have been suggested (16).

In 1984, the Analytical Chemistry and Polymer Technology Group of the Engineering School of São Carlos developed a polyurethane resin of vegetable origin extracted from castor oil. Polymers bear the advantage of being flexible in their processing and formulation, and they have excellent structural properties; they do not emit toxic vapors or irritants, and are biocompatible. Henning in 1989 observed its biocalcification in vivo and in vitro (17). Carvalho et al. (1997) observed osteointegration of such a polymer and reported the resorption and replacement of this polymer by bone tissue (16).

Therefore, the aim of this study was to evaluate the effect of bovine and human demineralized bone matrices, and a polyurethane resin derived from Ricinus communis oil, on the bone regeneration process.

\section{Materials and Methods}

Eighteen adult male New Zealand white rabbits (mean weight $2.9 \mathrm{~kg}$ ) of ages ranging from 3 to 6 months, which had reached skeletal maturity, were used in the study. They were divided into three groups of six each, depending on the biomaterial used for reconstruction of the cranial vault defect. Three animals from each group were killed at 7 and 15 weeks. The animals were grouped as follows:

Group 1: Bovine demineralized bone matrix versus control - In this group (six animals), each animal had one of its defects unfilled, serving as control, and these defects were allowed to heal spontaneously without the use of any grafting material. The contralateral defect was filled with granules of bovine demineralized bone matrix (OSSEOBOND ${ }^{T M}$, Pacific Coast Tissue Bank, Los Angeles, USA).

Group 2: Human demineralized bone matrix versus control - In Group 2 (six animals), granules of human demineralized bone matrix matrix (DEMBONE ${ }^{T M}$, Pacific Coast Tissue Bank) were placed into one defect, as in group 1. The contralateral defect was likewise filled with blood. It is important to note that Dembone was evaluated for osteoinductivity before implantation using established in vivo and in vitro tests.

Group 3: Ricinus communis polymer versus control For this group (six animals), a commercially available Ricinus communis polymer (AUG-EX ${ }^{T M}$, Poliquil, Araraquara, São Paulo, Brazil) was inserted on one side for comparison with the other side, which was not filled. The granules of this material were slightly larger than those of the other materials; thus, they were placed into the defects and carefully molded to achieve the desired contour.

Before the surgical procedure, each animal was premedicated according to its weight with an intramuscular injection of a mixture of ketamine and $2 \%$ of cloridrate of 2-(2, 6-xilidino)-5, 6-dihydro-4-H-1, 3-tiazin ( 0.5 $\mathrm{ml} / \mathrm{kg}$ ). After that, a full-thickness incision was made through skin and galea, along the midline of the scalp from a point midway between the base of the ears to a point approximately $5 \mathrm{~cm}$ anterior. Sharp subperiosteal dissection was performed to reflect the pericranium from the outer table of the cranial vault, exposing the parietal bones. An electric drill with a trephine bur was used under copious saline irrigation to create bilateral full-thickness calvarial defects (18). Two 10-mm-diameter defects were created, one on each side of the midline. The bone substitutes were placed directly onto the dura, replacing the volume of bone removed. The pericranium and skin were closed in layers with non-resorbable sutures (nylon / 4-0). Postoperatively, the animals received $1 \mathrm{ml}$ intraperitoneal injection of an antibiotic, Benzatin Penicillin. Each rabbit was caged and given food and water.

The animals were sacrificed 7 and 15 weeks after surgery; a total of three animals per group per slaughter period. Afterwards, the bone blocks were removed in order to prepare slides of the filled bone cavities for 
microscopic analysis.

The bone block specimens were placed in 10\% neutral buffered formalin and then decalcified in formic acid. Three coronal sections were made through the defect: one at the anterior edge, one in the middle, and one at the posterior edge of the defect. Each section was embedded in paraffin. Multiple $6-\mu \mathrm{m}$ sections were cut and stained with hematoxylin-eosin for light microscopy. The section through the middle of the defect (the greatest diameter across the defect) was used for quantification of the amount of new bone. Five slides through this section were analyzed by viewing the hematoxylin-eosin stained sections under light microscopy at $\times 10, \times 40$ and $\times 100$ magnification. The measurements were performed by the Professor of Oral and Maxillofacial Pathology at the Laboratory of Oral Pathology of the Dentistry School of Pernambuco, University of Pernambuco. The images shown in this study were captured using an analogue camera attached to the microscope. The photographs were then digitalized.

For measurement of the critical defect, the software image J version $1.39 \mathrm{u}$ (Freeware produced by Wayne Rasband in National Institute of Health, USA - available for download at http://rsb.info.nih.gov/ij/) was used. Linear measurements of the size of the particles and thickness of the new bony bridge formed in the period of 15 weeks were recorded. To standardize these measures, the area with the largest width of bone formation without interference of other tissues was taken as reference. The particles of larger dimension as presented in the photomicrograph were measured and value zero was given in the absence of implanted material (Fig. 1).

The experimental procedures had been approved by the Animal Care and Ethics Committee of Unicamp (University of Campinas, São Paulo, Brazil) (No. 183.1).

\section{Results}

\section{First period of sacrifice ( 7 weeks)}

Controls: Closure of the defect with a new bridge of bone interposed by strips of fibrous and osteoid connective tissue was seen. A marked reduction in thickness in the area of the defect was noted (double arrows in Fig. 2A).

Group I: OSSEOBOND ${ }^{T M}$ - Closure of the defect was noted with connective tissue, which varied from dense to myxomatous with areas of osteoid and new bone formed predominantly at the margins of the defect. A marked reduction in thickness in the area of the defect was noted (black arrows in Fig. 2B).

Group II: DEMBONE ${ }^{T M}$ - Closure of the defect was observed with new bone tissue interposed by connective tissue ranging from loose to fibrous with areas of osteoid (Fig. 2C). The thickness of the defect varied among the individuals studied, from no change to marked reduction of the thickness.

Group III: AUG-EX ${ }^{\circledR}$ - Virtually complete closure of the defect by mature bone tissue with partial recomposition of the internal cortical resulting in a new bone bridge between the edges. Osteoblastic activity, osteoid and new bone formation around the implanted material could be observed (black arrows in Fig. 2D).

\section{Second Period of Sacrifice (15 Weeks)}

Controls: Closure of the defect was seen with fibrous connective tissue and foci of new bone tissue. A marked reduction in thickness in the area of the defect was noted (double arrows in Fig. 3E).

Group I: OSSEOBOND ${ }^{T M}$ - Closure of the defect with a new bridge of bone and a moderate reduction in thickness in the area of the defect was observed (double arrows [margin defect - black arrows] in Fig. 3F).

Group II: DEMBONE ${ }^{T M}$ - Closure of the defect using fibrous connective tissue, with areas of new bone tissue involving particles of implanted material that were undergoing resorption, could be seen. A moderate reduction



Fig. 1 Use of Image to obtain linear measurements of the bony bridge and implanted particle. 


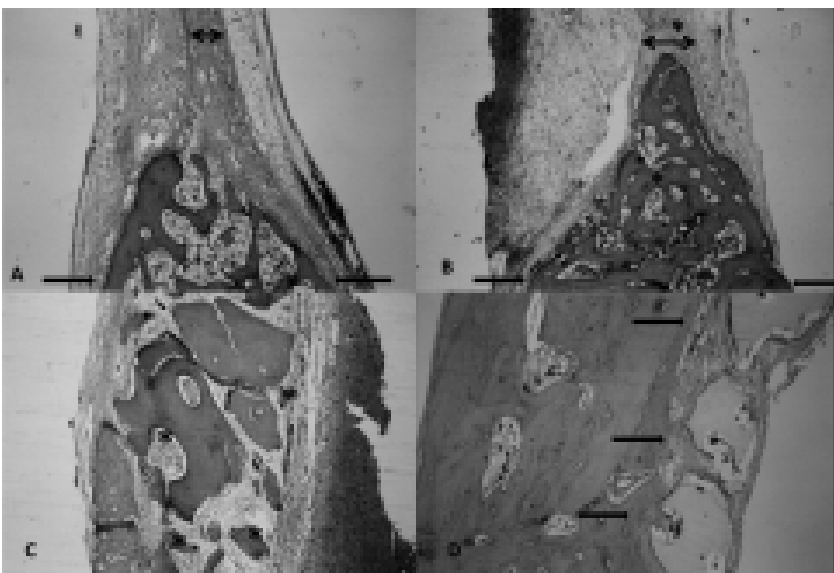

Fig. 2 Histological views at $\times 40$ magnification - Sacrifice post-7 weeks (A: Control group; B: Osseobond; C: Demobone; D: Aug-Ex)

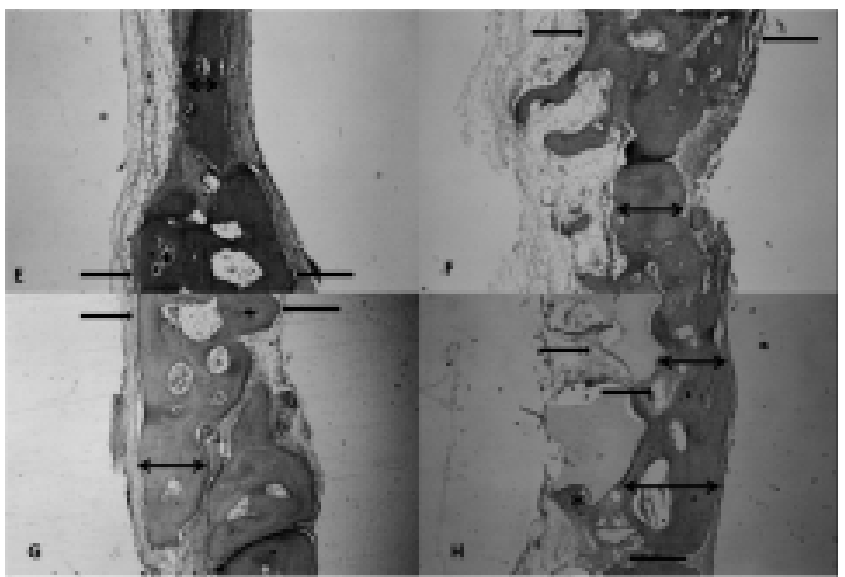

Fig. 3 Histological views at $\times 40$ magnification - Sacrifice post-15 weeks (E: Control group; F: Osseobond; G: Demobone; H: Aug-Ex).

Table 1 Measurements in linear units for the bone bridge and graft particles post 15 weeks

\begin{tabular}{lrrrr}
\hline 15 weeks post operative & Control & Aug-Ex & Osseobone & Dembone \\
\hline Bone bridge thickness & 294.425 & 684.205 & 874.353 & 1028.031 \\
Particles & 0 & 743.497 & 0 & 176.045 \\
Virtual defect thickness (bone + particles) & 294.425 & 1427.747 & 874.353 & 1204.481 \\
\hline
\end{tabular}

in thickness in the area of the defect was noted (see arrows in Fig. 3G).

Group III: $A U G-E X^{\circledR}$ - Partial closure of the defect with the formation of a bridge of mature bone (double arrows), fibrous connective tissue, and new bone formation surrounding the material used (black arrow). Osteoclastic activity was observed in one of the specimens on the periphery of the material (Fig. $3 \mathrm{H}$ ).

The linear measurements of the thickness of the new bone formed and the size of the particles of the material implanted at 15 weeks are shown in the table.

\section{Discussion}

The allograft materials used in this study were bovine and human demineralized bone matrices in particulate form. These matrices did not result in significantly more bone formation within the critical sized defect than did the polyurethane resin.

Over a 7-week period, particles of the materials surrounded by fibrous connective tissue and bone were observed in both the Ricinus communis polymer and demineralized bone groups. New bone formation was noticed at the margins of the defect, but a large quantity of connective tissues still remained in the demineralized bone group. In the polymer group, there was complete closure of the defect by mature bone tissue around the implanted material. This was also observed by Garcia and Barbosa (18) in relation to demineralized bone, and Laureano Filho et al. (17) when evaluating the Ricinus communis polymer. The best result was seen in the polymer groups compared to demineralized bone.

After 15 weeks, almost complete new bone formation was observed in all groups, with fusion of the margins in the experimental groups and fusion of bone in the control group accompanied by narrowing of the new bone. Such narrowing was not only seen in the polymer group. When healing of the defect took place in the control group, the previous bone thickness in the region could not be maintained, despite complete healing of the defect. In the same study, significant resorption of the particles of the demineralized bone occurred, which was faster in the bovine type than that of human origin. Therefore, it was not possible to maintain the same predefect thickness of the calvaria, unlike the polymer group, which consisted of a material with practically no resorption. The polymer had incorporated into the defect in a biocompatible manner 
during this period, thereby maintaining the thickness. As it becomes an integral part of the regenerated bone, this material may be used in the repair of defects in which bone contour should be preserved. However, in cases in which greater replacement of polymer by newly formed bone is required within a shorter period of time, such as in sinus lift for the placement of implants, it is suggested that the manufacturers of the compound reduce the particle size and also improve their morphology (19-21).

Resorption of the resin takes places much more slowly than in lyophilized bone matrices of human and bovine origin, as seen in the present study. It should also be borne in mind that the size of the polymer particles may vary from one manufacturer to another with different origins of the products, thus leading to different clinical outcomes, as previously observed by Schwartz et al. (22).

Although the polymer maintains the size of the defects, as evidenced in our study and by Lewardrowski et al. (23), the diminution of the particle size and change in their morphology might enhance the osteoinductive and osteoconductive properties and also preserve the volume of the receptor site of the graft for eventual bone replacement by the host itself. We observed, on the whole, by histological analysis, that the materials tested had a positive effect on the newly-formed bone of the defects $(17,20,24)$. The polymer maintains the volume of the defect for a long period; this could be considered clinically advantageous because the body has more time to substitute the particles by bone thus avoiding fibrosis. Another clinical advantage is the possibility to maintain the volume under soft tissues that can be useful in cases where the graft is performed not only to place implants but for esthetic purposes as well.

In conclusion, the use of osteconductive substitutes in bone regeneration is contraindicated in the repair of major defects. Duguy et al. (24) justify this statement by virtue of the fact that bone growth in this type of material is confined to the periphery of the implant. For this reason, other researchers $(25,26)$ suggest the combination of osteoinductive materials such as growth factors or even the use of bone matrices derived from tissues engineering, such as those studied by Schimming and Schmelzeisen (26) to obtain complete bone repair.

\section{References}

1. Wang L, Detamore MS (2007) Tissue engineering the mandibular condyle. Tissue Eng 13, 1955-1971.

2. Weiss P, Layrolle P, Clergeau LP, Enckel B, Pilet P, Amouriq Y, Daculsi G, Giumelli B (2007) The safety and efficacy of an injectable bone substitute in dental sockets demonstrated in a human clinical trial. Biomaterials 28, 3295-3305.

3. Canter HI, Vargel I, Mavili ME (2007) Reconstruction of mandibular defects using autografts combined with demineralized bone matrix and cancellous allograft. J Craniofac Surg 18, 95103.

4. Yildirim M, Spiekermann H, Biesterfeld S, Edelhoff D (2000) Maxillary sinus augmentation using xenogenic bone substitute material Bio-Oss in combination with venous blood. A histologic and histomorphometric study in humans. Clin Oral Implants Res 11, 217-229.

5. Wallace SS (2006) Maxillary sinus augmentation: evidence-based decision making with a biological surgical approach. Compend Contin Educ Dent 27, 662-668.

6. Esposito M, Grusovin MG, Coulthard P, Worthington HV (2006) The efficacy of various bone augmentation procedures for dental implants: a Cochrane systematic review of randomized controlled clinical trials. Int J Oral Maxillofac Implants 21, 696-710.

7. Raghoebar GM, Meijndert L, Kalk WW, Vissink A (2007) Morbidity of mandibular bone harvesting: a comparative study. Int J Oral Maxillofac Implants 22, 359-365.

8. Lawson R, Levin LS (2007) Principles of free tissue transfer in orthopaedic practice. J Am Acad Orthop Surg 15, 290-299.

9. Burg KJ, Porter S, Kellam JF (2000) Biomaterial developments for bone tissue engineering. Biomaterials 21, 2347-2359.

10. Beloti MM, Hiraki KR, Barros VM, Rosa AL (2003) Effect of the chemical composition of Ricinus communis polyurethane on rat bone marrow cell attachment, proliferation, and differentiation. $\mathrm{J}$ Biomed Mater Res A 64,171-176.

11. Peleg M, Garg AK, Misch CM, Mazor Z (2004) Maxillary sinus and ridge augmentations using a surface-derived autogenous bone graft. J Oral Maxillofac Surg 62, 1535-1544.

12. Jensen OT, Shulman LB, Block MS, Iacono VJ (1998) Report of the Sinus Consensus Conference of 1996. Int J Oral Maxillofac Implants 13, suppl, 11-45.

13. Lundgren S, Moy P, Johansson C, Nilsson H (1996) Augmentation of the maxillary sinus floor with particulated mandible: a histologic and histomorphometric study. Int J Oral Maxillofac Implants 11, 760-766.

14. Landi L, Pretel RW Jr, Hakimi NM, Setayesh R 
(2000) Maxillary sinus floor elevation using a combination of DFDBA and bovine-derived porous hydroxyapatite: a preliminary histologic and histomorphometric report. Int J Periodontics Restorative Dent 20, 574-583.

15. Hürzeler MB, Quiñones CR, Kirsch A, Schüpbach P, Krausse A, Strub JR, Caffesse RG (1997) Maxillary sinus augmentation using different grafting materials and dental implant in monkeys. Part III. Evaluation of autogenous bone combined with porous hydroxyapatite. Clin Oral Implants Res 8, 401-411.

16. Carvalho TL, Araújo CA, Teófilo JM, Brentegani LG (1997) Histologic and histometric evaluation of rat alveolar wound healing around polyurethane resin implants. Int J Oral Maxillofac Surg 26, 149152.

17. Laureano Filho JR, Castelo Branco Bde L, Andrade ES, Barbosa JR (2007) Histological comparison of demineralized bone matrix and the Ricinus communis polymer on bone regeneration. Braz $\mathrm{J}$ Otorhinolaryngol 73, 186-192.

18. Garcia RR, Barbosa JR (2000) Histologic study of a bovine demineralized bone matrix on bone repair process in rabbits calvaria. Indian J Dent Res 11, 131-138.

19. An HS, Lynch K, Toth J (1995) Prospective comparison of autograft vs. allograft for adult osterolateral lumbar spine fusion: differences among freeze-dried, frozen, and mixed grafts. J Spinal Disord 8, 131-135.

20. Boëck-Neto RJ, Gabrielli M, Lia R, Marcantonio E, Shibli JA, Marcantonio E Jr (2002)
Histomorphometrical analysis of bone formed after maxillary sinus floor augmentation by grafting with a combination of autogenous bone and demineralized freeze-dried bone allograft or hydroxyapatite. J Periodontol 73, 266-270.

21. Maiorana C, Redemagni M, Rabagliati M, Salina S (2000) Treatment of maxillary ridge resorption by sinus augmentation with iliac cancellous bone, anorganic bovine bone, and endosseous implants: a clinical and histologic report. Int J Oral Maxillofac Implants 15, 873-878.

22. Schwartz Z, Mellonig JT, Carnes DL Jr, de la Fontaine J, Cochan DL, Dean DD, Boyan BD (1996) Ability of commercial demineralized freeze-dried bone allograft to induce new bone formation. $J$ Periodontol 67, 918-926.

23. Lewandrowski KU, Bondre S, Gresser JD, Silva AE, Wise DL, Trantolo DJ (1999) Augmentation of osteoinduction with a biodegradable poly(propylene glycol-co-fumaric acid) bone graft extender. A histologic and histomorphometric study in rats. Biomed Mater Eng 9, 325-334.

24. Duguy N, Petite H, Arnaud E (2000) Biomaterials and osseous regeneration. Ann Chir Plast Esthet 45, 364-376. (in French)

25. Vandersteenhoven JJ, Spector M (1983) Osteoinduction within porous pollysulfone implants at extraosseous sites using demineralized allogenic bone matrix. J Biomed Mater Res 17, 793-806.

26. Schimming R, Schmelzeinsen R (2004) Tissueengineered bone for maxillary sinus augumetation. J Oral Maxillofac Surg 62, 724-729. 